\title{
Treatment of Hyponatremia with Tolvaptan in a Patient after Neurosurgical Treatment of a Pituitary Tumor: Case Report and Review of Literature
}

\author{
Shinya Ichimura ${ }^{1}$ Rudolf Fahlbusch ${ }^{1}$ Wolf Lüdemann ${ }^{1}$ \\ ${ }^{1}$ Department of Neurosurgery, International Neuroscience Institute, \\ Hannover, Germany \\ J Neurol Surg Rep 2015;76:e279-e281. \\ Address for correspondence Shinya Ichimura, MD, PhD, Department \\ of Neurosurgery, International Neuroscience Institute, Hannover, \\ Germany, Rudolf Pichlmayr Str. 4, 30625 Hannover, Germany \\ (e-mail: shinya3917@gmail.com).
}

\begin{abstract}
Hyponatremia is a frequent complication following pituitary surgery. We report a case with hyponatremia after surgery of a pituitary adenoma that was successfully treated with tolvaptan. A 68-year-old man with a pituitary tumor presented with mild hyponatremia (133 mEq/L) before surgery. The patient developed hyponatremia (125 mEq) 4 days postsurgery, and 10\% sodium chloride was infused. Seven 7 days postsurgery, hyponatremia was improved ( $132 \mathrm{mEq} / \mathrm{L})$, and tolvaptan $15 \mathrm{mg}$ was given

Keywords

- hyponatremia

- pituitary tumor

- tolvaptan orally as a single dose instead of the $10 \%$ sodium chloride infusion. His serum sodium remained within normal limits. The syndrome of inappropriate antidiuretic hormone secretion (SIADH) after pituitary surgery most probably led to the hyponatremia, and tolvaptan was effective because it is an oral vasopressin receptor antagonist.
\end{abstract}

\section{Introduction}

Pituitary surgery is often accompanied by disturbances of osmoregulation that may result from manipulation or vascular alterations of the neurohypophysis. ${ }^{1}$ Hyponatremia after pituitary surgery is typically due to syndrome of inappropriate antidiuretic hormone secretion (SIADH) and typically associated with a euvolemic state. ${ }^{2}$ Here we report a case with hyponatremia after pituitary surgery that was successfully treated with tolvaptan. We found only four neurosurgical reports about tolvaptan in the literature. ${ }^{1-4}$

\section{Case Report}

A 68-year-old man was detected with an infra- and suprasellar tumor with symptomatic panhypopituitarism and adynamia (-Fig. 1). He was treated with hormonal substitution including testosterone for $>5$ years. Visual field disturbance led him to admission and surgery. The preoperative serum sodium was $133 \mathrm{mEq} / \mathrm{L}$ (-Fig. 2), which was slightly lower

received

April 27, 2015

accepted after revision

August 11, 2015

published online

October 25, 2015 than the normal serum sodium level between 135 and $145 \mathrm{mEq} / \mathrm{L}$. An endonasal transsphenoidal approach was performed, and the tumor was totally removed. Four days postsurgery, the patient developed hyponatremia (125 $\mathrm{mEq} / \mathrm{L}$ ) and fell into a stupor. We infused $10 \%$ sodium chloride at a level of $1 \mathrm{~mL}$ per hour because the patient could not swallow. The hyponatremia improved gradually $(132 \mathrm{mEq} / \mathrm{L})$ 7 days postsurgery, and the patient could then swallow because he had recovered consciousness. He patient was given one 15-mg tablet orally of tolvaptan (Otsuka, Tokushima, Shikoku, Japan) per day. We stopped the infusion of $10 \%$ sodium chloride because the serum sodium level improved enough to keep the patient conscious. The patient was able to be discharged from the hospital. His serum sodium remained within normal limits (-Fig. 2).

\section{Discussion}

Hyponatremia has been described following pituitary surgery, with an incidence varying from 3 to $25 \%$ depending on
License terms

Stuttgart · New York

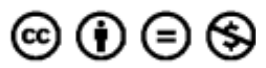



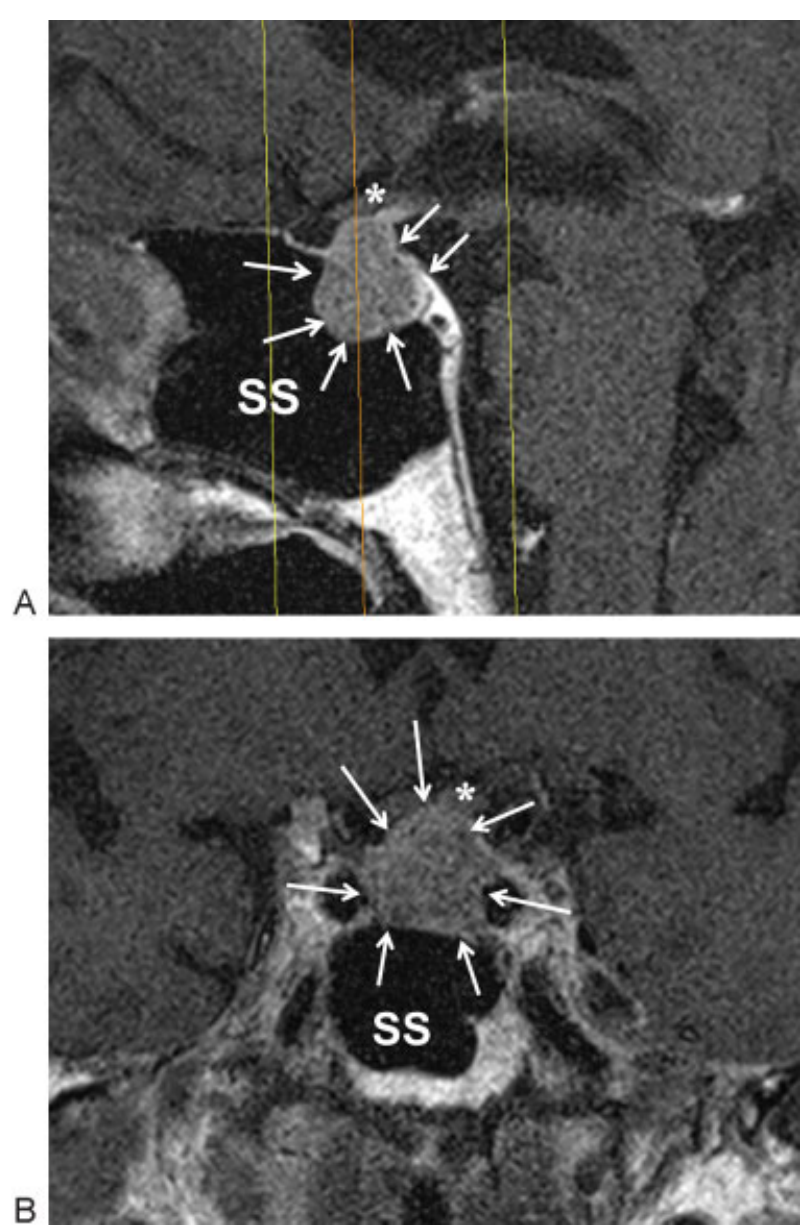

Fig. 1 T1-weighted magnetic resonance images with gadolinium enhancement showing a pituitary tumor. (A) Sagittal view. (B) Coronal view. Arrows, tumor; asterisks, optic nerve; SS, sphenoid sinus.

the series. ${ }^{1,3}$ The presence of preoperative hypopituitarism makes postoperative hyponatremia more likely. ${ }^{5}$

The timing of postoperative hyponatremia has been reported both as an early incidence peak occurring around

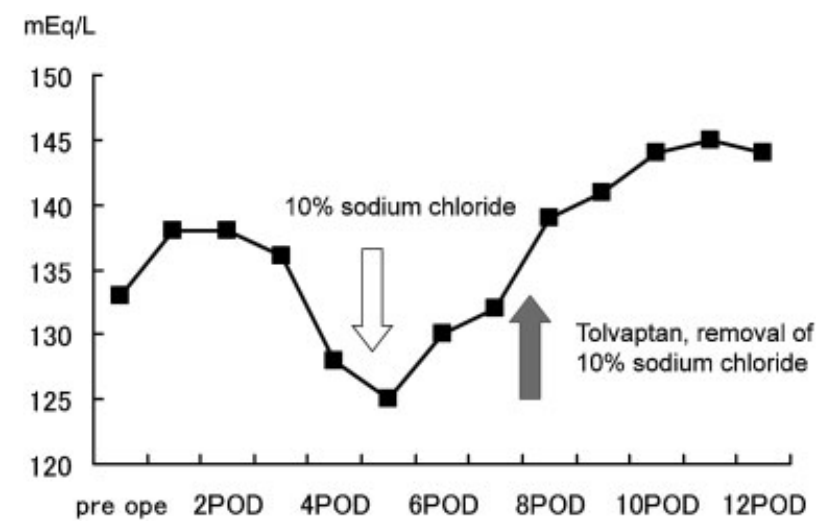

Fig. 2 Changes of serum sodium. The serum sodium on admission was $133 \mathrm{mEq} / \mathrm{L}$, mild hyponatremia. Four days postsurgery, the serum sodium decreased to $125 \mathrm{mEq} / \mathrm{L}$, and then $10 \%$ sodium chloride at 1 $\mathrm{mL} / \mathrm{h}$ was infused. The serum sodium improved to $132 \mathrm{mEq} / \mathrm{L} 7$ days postsurgery. Tolvaptan was given orally, and $10 \%$ sodium chloride was discontinued. POD, postoperative day; pre ope, preoperative. postoperative day $2,{ }^{5}$ as well as a slightly more delayed peak typically occurring between postoperative days 7 and 9.,7 Hyponatremia following pituitary surgery is predominantly due to SIADH because mechanical irritation of the posterior pituitary lobe or the pituitary stalk is thought to be the underlying pathophysiologic cause of uncontrolled antidiuretic hormone release. ${ }^{8,9}$ Cerebral salt wasting syndrome is unlikely after pituitary surgery. ${ }^{10}$

Tolvaptan, an oral vasopressin receptor antagonist, is from a relatively new therapeutic class of agents for the management of hyponatremia. Nephrologists have long believed that vasopressin receptor antagonists may be particularly effective at treating SIADH due to intracranial disorders, trauma, or neurosurgery because they are the most physiologic approach to treat this common electrolyte disturbance. ${ }^{8,11}$ There are three receptors for vasopressin, of which the V-2 receptors mediate the antidiuretic response. The vasopressin receptor antagonists prevent binding of vasopressin, thereby causing loss of water without altering sodium and potassium excretion. $^{12-14}$

In this case, tolvaptan was effective to improve the hyponatremia that occurred 4 days postsurgery in a relatively early phase. When the patient can swallow, it is much easier to administer tolvaptan than to infuse sodium chloride. In addition, the patient can be discharged earlier. Still we cannot conclude that our case presents a normal resolution of postoperative SIADH. But the preoperative hyponatremia even on admission makes this case special. We will gather more cases to analyze in the future.

\section{References}

1 Jahangiri A, Wagner J, Tran MT, et al. Factors predicting postoperative hyponatremia and efficacy of hyponatremia management strategies after more than 1000 pituitary operations. J Neurosurg 2013;119(6):1478-1483

2 Buckley MS, Patel SA, Hattrup AE, Kazem NH, Jacobs SC, Culver MA. Conivaptan for treatment of hyponatremia in neurologic and neurosurgical adults. Ann Pharmacother 2013;47(9):1194-1200

3 Janneck M, Burkhardt T, Rotermund R, Sauer N, Flitsch J, Aberle J. Hyponatremia after trans-sphenoidal surgery. Minerva Endocrinol 2014;39(1):27-31

4 Nathan BR. Cerebral correlates of hyponatremia. Neurocrit Care 2007;6(1):72-78

5 Guerrero R, Pumar A, Soto A, et al. Early hyponatraemia after pituitary surgery: cerebral salt-wasting syndrome. Eur J Endocrinol 2007;156(6):611-616

6 Kelly DF, Laws ER Jr, Fossett D. Delayed hyponatremia after transsphenoidal surgery for pituitary adenoma. Report of nine cases. J Neurosurg 1995;83(2):363-367

7 Olson BR, Gumowski J, Rubino D, Oldfield EH. Pathophysiology of hyponatremia after transsphenoidal pituitary surgery. J Neurosurg 1997;87(4):499-507

8 Hannon MJ, Thompson CJ. Neurosurgical hyponatremia. J Clin Med 2014;3(4):1084-1104

9 Sterns R, Hix J. Hyponatremia: vasopressin antagonists in hyponatremia: more data needed. Nat Rev Nephrol 2011;7(3): 132-133

10 Fraser JF, Stieg PE. Hyponatremia in the neurosurgical patient: epidemiology, pathophysiology, diagnosis, and management. Neurosurgery 2006;59(2):222-229; discussion 222-229 
11 Sherlock M, O'Sullivan E, Agha A, et al. Incidence and pathophysiology of severe hyponatraemia in neurosurgical patients. Postgrad Med J 2009;85(1002):171-175

12 Berl T, Quittnat-Pelletier F, Verbalis JG, et al; SALTWATER Investigators. Oral tolvaptan is safe and effective in chronic hyponatremia. J Am Soc Nephrol 2010;21(4):705-712
13 Schrier RW, Gross P, Gheorghiade M, et al; SALT Investigators. Tolvaptan, a selective oral vasopressin V2-receptor antagonist, for hyponatremia. N Engl J Med 2006;355(20):2099-2112

14 Verbalis JG, Goldsmith SR, Greenberg A, et al. Diagnosis, evaluation, and treatment of hyponatremia: expert panel recommendations. Am J Med 2013;126(10, Suppl 1):S1-S42 